\title{
A rare and isolated presentation of primary cutaneous anaplastic large cell lymphoma
}

\author{
Maitri Shah ${ }^{1}$, Manoj Pawar ${ }^{1 凶}$, Vijay Zawar $^{1}$
}

\begin{abstract}
Primary cutaneous anaplastic large cell lymphoma is a $\mathrm{CD} 30+$ lymphoproliferative disorder of the skin characterized by the absence of nodal and visceral involvement, low recurrence rate, spontaneous remission, and tendency to occur in patients older than 20 years. The case presented here is of a 15-year-old boy with grouped papular lesions arranged in an annular fashion with a central clearing on his right arm for 4 months that was diagnosed with a case of anaplastic lymphoma kinase-negative primary cutaneous $\mathrm{CD}_{30}$ + anaplastic large cell lymphoma. The CT scan, bone marrow biopsy, and laboratory data ruled out systemic involvement. He was treated with oral methotrexate $10 \mathrm{mg}$ once a week, but was lost to follow-up.
\end{abstract}

Keywords: primary cutaneous anaplastic large cell lymphoma, isolated, methotrexate

Received: 12 July 2017 | Returned for modification: 24 July 2017 | Accepted: 27 August 2017

\section{Introduction}

Anaplastic large cell lymphoma (ALCL) is considered a T-cell nonHodgkin lymphoma that can be classified into two major groups based on distinct clinical, genetic, and immunophenotypic behavior. The first group consists of $\mathrm{CD} 30+\mathrm{T}$-cell lymphoproliferative disorders, which include primary cutaneous ALCL (PC-ALCL)which may be either anaplastic lymphoma kinase (ALK)-positive or ALK-negative-at the malignant end, and the morphologically and immunohistochemically identical lymphomatoid papulosis (LyP), at the benign end of the spectrum. The second group is systemic ALCL (S-ALCL), which is further divided into ALK-positive and ALK-negative S-ALCL (1). The case presented here is one of ALK-negative, CD30+ PC-ALCL in a 15-year-old boy.

\section{Case report}

A 15-year-old adolescent boy, otherwise healthy, presented with elevated skin-colored lesions on his right arm that had persisted for 4 months. The occurrence started with a few discrete, elevated, solid skin-colored lesions, associated with mild itching and pain on pressure. Later the lesions increased in size and number while the few central lesions healed, leading to the presenting configuration. There was no history of insect bite, trauma, local applications, illicit drug use, allergy, or any illness prior to the onset of these lesions. There was no history of fever, weight loss, or night sweats. On local examination, there were multiple, discrete skincolored to erythematous-violaceous papules arranged in annular fashion with central clearing, and a few of them had coalesced to form a plaque over the lateral aspect of right arm (Fig. 1). Systemic examination, including lymph node examination, did not reveal any significant findings. A skin biopsy obtained from the border of the lesion was sent for histopathology, fungal stains, and mycological culture. Histopathology revealed an interstitial infiltrate of predominantly large lymphocytes and plasmacytoid cells involving the whole reticular dermis and extending into the subcutis (Figs. 2-3). Immunohistochemical tests were positive for $\mathrm{CD}_{30+}$ large cells but negative for ALK expression. Results of all labora- tory examinations, including complete blood cell count, peripheral blood smear, bone marrow biopsy, and CT scan of chest and abdomen, demonstrated no other systemic involvement. Thus, a final diagnosis of ALK-negative PC-ALCL confined only to skin was made. The patient was given oral methotrexate $10 \mathrm{mg}$ once a week and folic acid $5 \mathrm{mg}$ once daily the other 6 days. The patient was lost to follow-up, making it impossible to observe the efficacy of methotrexate in PC-ALCL.

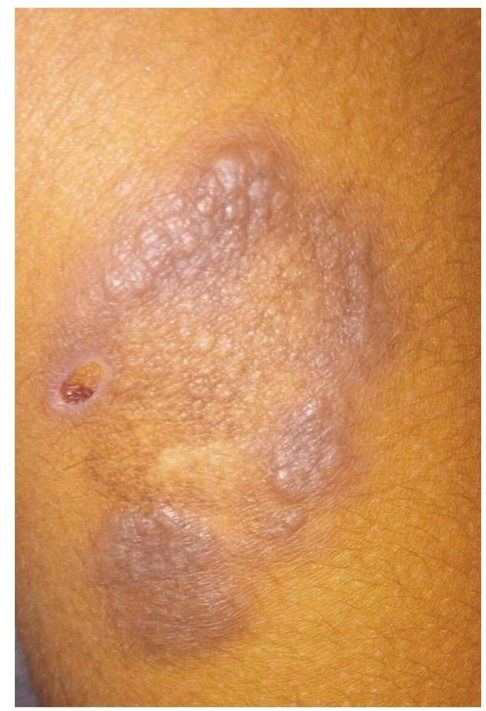

Figure 1 | Multiple skin-colored to erythematous-violaceous discrete papules with a few coalescing to form a plaque.

\section{Discussion}

PC-ALCL is a CD30+ lymphoproliferative disorder of the skin consisting of cells with an anaplastic, pleomorphic, or immunoblastic cytomorphology with $>75 \%$ of the tumor cells expressing CD30 (Ki1) antigen. $\mathrm{CD} 30+$ lymphoproliferative disorders account for $25 \%$ to $30 \%$ of primary cutaneous lymphomas (1). Mycosis fungoides is the most common cutaneous T-cell lymphoma, and PC-ALCL is the second most common. The most commonly affected age group is 50 to 70 years, but a few cases have been reported in the pediatric 


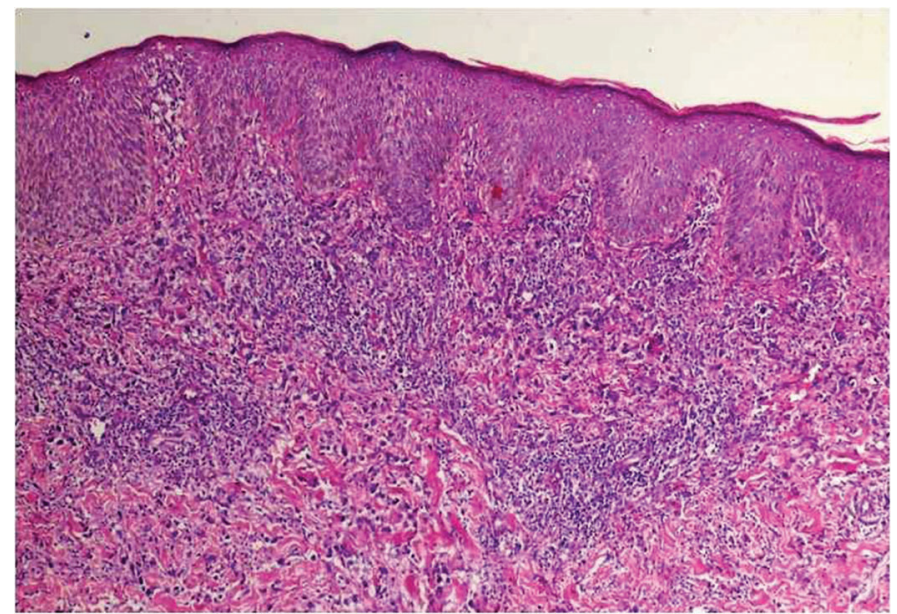

Figure 2 | Interstitial infiltrate of predominantly large lymphocytes and plasmacytoid cells involving the whole reticular dermis and extending to the subcutis (H\&E 40x).

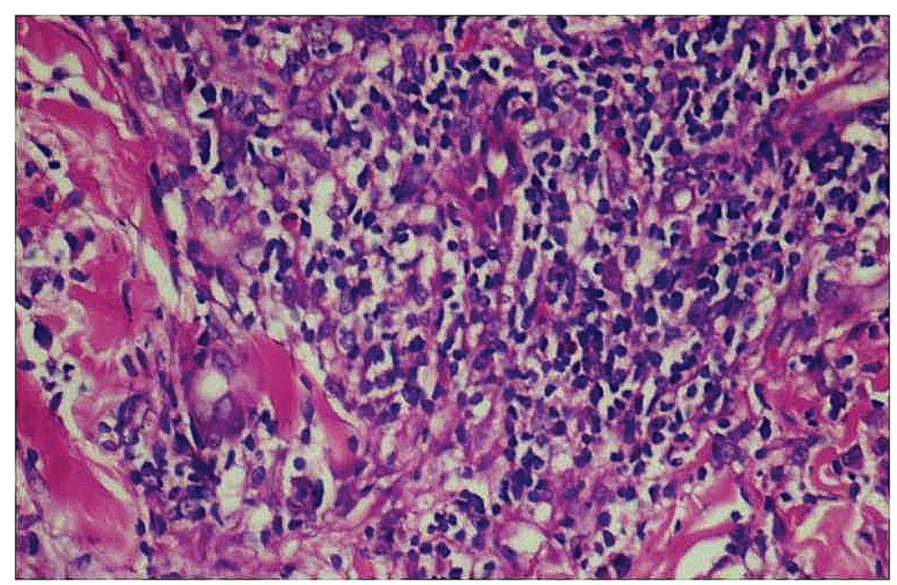

Figure 3 | Same histology at $100 \times$ magnification.

age group (2 to 4 years). PC-ALCL with nodal or visceral involvement at presentation is common after age 20, and men are more often affected than women (5). PC-ALCL may arise de novo (i.e., as a primary form) or in a secondary form that arises from the anaplastic transformation of another lymphoma (1).

PC-ALCL presents as one or more rapidly progressive, asymptomatic, localized, grouped or multifocal nodules (which may ulcerate), and occasionally as papules and plaques mainly on the upper half of the body, which persist for at least 3 to 4 weeks (1). Disseminated or grouped multiple lesions of PC-ALCL are seen in $20 \%$ of cases, whereas regional lymph node involvement manifesting as lymphadenopathy occurs in $25 \%$ of cases (6).

Histology and immunohistochemistry is of the utmost impor- tance in the diagnosis and staging of PC-ALCL. The histology shows large, irregular polygonal cells arranged in sheets extending throughout the dermis and, sometimes, the subcutis. Large lymphoid cells, also known as hallmark cells-with embryonic nuclei, multiple prominent nucleoli, and abundant eosinophilic cytoplasm-are characteristic but can be absent. ALK positivity was initially considered evidence of systemic ALCL; however, ALK+ cases of PC-ALCL have been described, mainly in children $(1,6)$.

Differentials to keep in mind when evaluating a case of PCALCL are B-cell lymphoma, leukemia cutis, lymphocytoma cutis, LyP, and other reactive conditions such as arthropod bites, drug eruptions, and viral infections. A few cases of PC-ALCL have resembled eczema, pyoderma gangrenosum, pyogenic granuloma, morphea, and squamous cell carcinoma (7). LyP, especially type C, closely mimics PC-ALCL because histologic, morphologic, and immunophenotypic features of both diseases overlap; however, the recurrent and regressing nature of the crops of papules and nodules in LyP is distinctive (1).

The localized lesions of PC-ALCL can be treated with excision, low-dose methotrexate, topical corticosteroids, topical mechlorethamine, oral antibiotics, phototherapy, interferon alfa, and systemic retinoids, including bexarotene. Chemotherapy is not recommended because it does not prevent recurrence and has many adverse effects (9). Local radiation is more appropriate for a higher tumor burden. When disseminated, the disease is best treated with multiagent systemic chemotherapy. A novel monoclonal anti-CD30 antibody linked with the cytotoxic compound monomethyl auristatin E (e.g., brentuximab vedotin) has shown efficacy in PC-ALCL. Many cases of PC-ALCL refractory to systemic chemotherapy have been treated with allogeneic and autologous stem cell transplantation with variable response (1).

Twenty to $42 \%$ of PC-ALCL patients show spontaneous regression. Patients younger than 60 years with spontaneous regression have a good prognosis, whereas extensive limb disease- especially lower limb involvement-extracutaneous disease, and an age greater than 60 years are poor prognostic indicators. The primary cutaneous form usually runs an indolent course, and spontaneous remissions occur in approximately $25 \%$ of these cases, in which dissemination is also less common $(1,8)$.

PC-ALCL may have myriad cutaneous presentations and, because of the rarity of this condition, its diagnosis is often missed or delayed. The diagnosis of PC-ALCL hinges on good clinical, histologic, and immunochemistry findings.

The patient described here presented with an ALK-negative, CD-30+ PC-ALCL without systemic involvement. This is an unusual clinical spectrum of ALCL.

\section{References}

1. Brown RA, Fernandez-Pol S, Kim J. Primary cutaneous anaplastic large cell lymphoma. J Cutan Pathol. 2017;44:570-7.

2. Mendiratta V, Gandhi N, Rana S, Shukla S, Ramchander. Isolated cutaneous involvement in a child with nodal anaplastic large cell lymphoma. Indian J Dermatol Venereo Leprol. 2016;82:53-6.

3. Mahajan VK, Jindal R. Primary cutaneous anaplastic large cell lymphoma in a child simulating primary cutaneous Hodgkin's disease. Indian J Dermatol Venereol Leprol. 2016;82:98-101.

4. de Bruin PC, Beljaards RC, van Heerde P, Van Der Valk P, Noorduyn LA, Van Krieken JH, et al. Differences in clinical behavior and immunophenotype between primary cutaneous and primary nodal anaplastic large cell lymphoma of T-cell or null cell phenotype. Histopathology. 1993;23:127-35.

5. Newlove T, Loyd A, Patel R, Jelinek J, Latkowski JA. Primary cutaneous anaplastic large-cell lymphoma. Dermatol Online J. 2010;16:2.

6. Kumaran MS, Jithendriya M, Nagaraj P, Tirumalae R, Jayaseelan E. Anaplastic lymphoma kinase-positive primary cutaneous anaplastic large cell lymphomais it a new variant? Indian J Dermatol Venereol Leprol. 2012;78:354-7.

7. Krishnan J, Tomaszewski MM, Kao GF. Primary cutaneous $\mathrm{CD}_{30}$-positive anaplastic large cell lymphoma. Report of 27 cases. J Cutan Pathol. 1993;20:193-202.

8. Bekkenk MW, Geelen FA, van Voorst Vader PC, Heule F, Geerts ML, van Vloten WA, et al. Primary and secondary cutaneous $\mathrm{CD}_{30}+$ lymphoproliferative disorders: a report from the Dutch Cutaneous Lymphoma Group on the long-term follow-up data of 219 patients and guidelines for diagnosis and treatment. Blood. 2000;95:3653-61.

9. Liu HL, Hoppe RT, Kohler S, Harvell JD, Reddy S, Kim YH. CD30+ cutaneous lymphoproliferative disorders: the Stanford experience in lymphomatoid papulosis and primary cutaneous anaplastic large cell lymphoma. J Am Acad Dermatol. 2003;49:1049-58. 